\title{
A utilização de mídias sociais no marketing pessoal: um estudo sobre o posicionamento estratégico de personalidades participantes do Big Brother Brasil
}

\section{1}

The use of social media in personal marketing: a study on the strategic positioning of personalities participating in the Big Brother Brasil 2021

El uso de las redes sociales en el marketing personal: un estudio sobre el posicionamiento estratégico de las personalidades que participan en el Big Brother Brasil 2021

\section{Resumo}

Reality shows possuem grande alcance no Brasil, sendo capazes de promover retornos financeiros significativos e gerar uma expressiva audiência de telespectadores. Como consequência do alcance massificado do programa, as personalidades que nele competem têm sua imagem exposta ao público brasileiro de uma maneira desmedida. Nesse sentido, o objetivo deste trabalho é estudar como os reality shows podem favorecer o fortalecimento da imagem pessoal dos participantes por meio de Marketing Digital a fim de que os integrantes tornam-se marcas de valor para os negócios. Propõe-se, assim, analisar estudos de caso para identificar a estratégia utilizada nas redes sociais, a reação do público em relação ao posicionamento do participante e a quantificação dos ganhos em termos de seguidores e parcerias. Como aprendizado, foi constatado que a imagem pessoal dos participantes é favorecida ao passo que as mídias sociais são utilizadas estrategicamente, construindo uma forte relação com uma rede de apoiadores e reforçando a identidade sólida do participante durante e após a permanência no reality show. Quando bem utilizado, o Marketing Digital pode criar um público fiel ao participante e, assim, transformá-lo em uma marca de valor para os negócios.

Palavras-chave: Big Brother Brasil; Marketing pessoal; Marketing digital; Instagram; Twitter. 


\begin{abstract}
Reality shows have a great reach in Brazil. They are able to promote significant financial returns and generate an expressive audience of telespectateurs. As a consequence of the massifying reach of realities, the personalities competing in it have their images exposed to the Brazilian public in an unmeasurable way. The objective of this essay is to study how the reality shows can favor the fortification of the participants' personal image throughout Digital Marketing aiming to turn the participants into valuable brands for business. It is purposed to analyse case studies to identify the used strategy on social media, the public reaction to the participant positioning and the gains quantification in terms of followers and partnerships. It was learned that the participants' personal image is favored when social media are strategically used, building a strong relationship with a fan network and reinforcing the solid identification of the participant during and after the reality show. When well used, Digital Marketing can create a loyal public to the participant and, so, turn him/her into a valuable brand for business.
\end{abstract}

Keywords: Big Brother Brasil; Personal marketing; Digital marketing; Instagram; Twitter.

\title{
Resumen
}

Los reality shows tienen un amplio alcance en Brasil, pudiendo promover importantes retornos financieros y generar una audiencia expresiva de espectadores. Como resultado del alcance masivo del programa, las personalidades que compiten en él tienen su imagen expuesta al público brasileño de manera inconmensurable. En este sentido, el objetivo de este trabajo es estudiar cómo los reality shows pueden favorecer el fortalecimiento de la imagen personal de los participantes a través del Marketing Digital para que los integrantes se conviertan en marcas de valor para el negocio. Se propone, por tanto, analizar estudios de caso para identificar la estrategia utilizada en las redes sociales, la reacción del público en relación al posicionamiento del participante y la cuantificación de ganancias en términos de seguidores y alianzas comerciales. Como experiencia de aprendizaje, se encontró que se favorece la imagen personal de los participantes mientras que las redes sociales se utilizan estratégicamente, construyendo una relación sólida con una red de simpatizantes y reforzando la sólida identidad del participante durante y después de la permanencia en el reality show. Cuando se usa bien, el Marketing Digital puede crear una audiencia leal al participante y, así, transformarlo en una marca de valor para el negocio.

Palabras clave: Big Brother Brasil; Personal marketing; Digital marketing; Instagram; Twitter.

\section{Introdução}

Desde o início do século XXI, a televisão brasileira tem desenvolvido reality shows com alto alcance midiático. Como reality show, compreende-se um programa que une pessoas reais competindo por um prêmio, seja em situação de confinamento ou em encontros periódicos, sem necessariamente haver o convívio integral entre os participantes. Embora estes programas tenham sido criados principalmente para o entretenimento dos telespectadores, suas funções se estenderam ao longo do tempo: atualmente, esta categoria televisiva possui um maior viés mercadológico (Brittos \& Barbosa, 2010) e é utilizada para promover marcas patrocinadoras, gerar fama aos participantes e alavancar retornos desmedidos às emissoras.

Programas de reality show como o Big Brother Brasil (BBB) têm um alcance estrondoso: a estreia da edição de 2021 alcançou mais de 43 milhões de espectadores! Além disso, de acordo com dados oficiais do Guinness Book, "o maior número de votos públicos recebidos por um programa de televisão pertence ao Big Brother Brasil 20” (GUINNESS BOOK, 2020), com cerca de 1,5 bilhão de votos em uma única eliminação. O engajamento não permanece apenas nas plataformas da emissora; os telespectadores também participam das discussões levantadas nos realities por meio das redes sociais: em 2020, o Twitter recebeu 278 milhões de tuítes sobre o BBB, sendo o assunto mais comentado do mundo no período.

Devido ao gigantesco alcance dos realities, é vantajoso às grandes marcas utilizar o espaço para se promover. Como exemplo, pode-se citar o merchandising do McDonald's no Big Brother Brasil 2021: a empresa investiu ao menos R\$78 milhões para estampar sua marca em uma festa do reality, expondo seus produtos com food appeal e inserindo novos produtos à venda, como pijamas e meias. Esta ação foi altamente mencionada e elogiada por especialistas, pois possibilitou muitos retornos à lanchonete, uma vez que a busca por termos como "mc donalds" e "méqui" mais do que quadruplicaram durante a exibição do programa, segundo análise do Google Trends.

Além das grandes marcas, as personalidades participantes também podem se beneficiar do reality, aumentando o engajamento de seus perfis e o número de fãs. Na história do BBB, há muitos nomes conhecidos que fizeram uma gestão de 
imagem com promoção estratégica, como Manu Gavassi, Grazi Massafera e Sabrina Sato. Em 2021, o destaque deste trabalho vai para Juliette Freire Feitosa, campeã desta edição, nordestina e advogada; e Gilberto José Nogueira Júnior, que ficou conhecido, após grande êxito no reality, como Gil do Vigor, economista e LGBTQIA +.

Da mesma forma, algumas personalidades obtiveram resultados negativos em decorrência de suas estratégias em relação à gestão de imagem. Em 2021, o foco foi Karoline dos Santos Oliveira, que se popularizou como Karol Conká, cantora e figura pública nacional antes de entrar no programa e, por isso, seu caso também será abordado neste trabalho.

Conforme é apresentado no tópico Análise Resultados deste estudo, as ações dos participantes dentro dos programas impactam diretamente sua popularidade do lado de fora e, segundo as teorias acerca do marketing pessoal, essas ações, possuem o poder de aumentar os resultados positivos para o participante (Silva, et al., 2019); mas, embora o comportamento individual seja relevante, é imprescindível uma gestão da imagem por meio de mídias sociais para promover engajamento às personalidades, considerando que as redes possuem um alcance massificado entre os telespectadores e a promoção por meio do marketing digital possibilitaria mais reconhecimento desse público e possibilidades de compra pelo mesmo (Umami \& Darma, 2021). Assumindo o grande poder da exposição televisiva, a pergunta orientadora deste trabalho é: os membros dos reality shows aproveitam os resultados obtidos pela exposição demasiada que o programa lhes oferece, para fortalecer sua imagem por meio de marketing digital, a fim de que os integrantes possam tornar-se marcas de valor para os negócios?

A fim de responder e estudar esta questão, este trabalho possui como objetivo geral compreender como os reality shows podem favorecer o fortalecimento da imagem pessoal dos participantes por meio de Marketing Digital a fim de que os integrantes tornam-se marcas de valor para os negócios.

Como objetivos específicos, tem-se: I.) estudar as estratégias utilizadas; II.) analisar como os participantes otimizam a utilização das redes sociais; e III.) quantificar os ganhos de seguidores e parcerias durante e após a participação no programa.

Dentre as principais justificativas para a elaboração deste trabalho, cita-se: nicho de mercado pouco estudado; oportunidades de inovação no marketing pessoal; estudo sobre a relação entre programas de entretenimento e marketing digital; e relevância dos reality shows na televisão e na cultura brasileira.

Em um primeiro momento, este artigo irá se desenvolver a partir de seu referencial teórico, logo após a metodologia utilizada será apresentada, precedendo às seções dos resultados e discussões apurados e, por fim, as considerações finais deste estudo.

\section{Referencial Teórico}

\subsection{Reality show}

O assunto "reality show" não é muito encontrado no meio acadêmico, portanto, poucos autores escrevem sobre esse tema. Dito isso, é possível facilmente perceber que não há uma definição consensual do que seja um reality show.

Dentre os autores pesquisados, Rocha $(2009$, p. 2), foi a que melhor ofereceu uma explicação concisa do termo em questão. A autora fez um paralelo entre Reality TV e Reality Show, onde define sobre a Reality TV: "Trata-se de uma estratégia na qual o referente, o mundo sensível e real, o mundo vivido se torna o grande protagonista da TV, ele é o personagem principal e estrutura essa forma de televisão que tem sido denominada como reality TV, a TV realidade". Após isso, a autora especifica que o Reality Show é uma variedade de Reality TV, e que essa categoria é a mais popular, uma vez que está entre as mais relacionadas com o tema.

Os autores (Folayan, et al., 2021) informam a relação que os reality show têm com o seu público, concluindo na sua pesquisa que da mesma forma que o público de mídias de massa são impactados pelo o conteúdo apresentado, quanto o público impacta essas mídias de massa influenciando e definindo o sucesso do programa. 
Em um âmbito mais voltado para o mercado, existem autores que dizem que realities "são fenômenos mundiais no meio televisivo, tendo como mote a apresentação da realidade de atores sociais num cotidiano inventado essencialmente por interesses mercadológicos" (Brittos \& Barbosa, 2010, p. 219). Diante dessa realidade mercadológica, (Rocha, 2009), afirma que reality shows possuem um impacto tão estrondoso, que seu alcance não fica apenas na televisão, mas atravessa os limites televisivos, afetando os outros sistemas de comunicação.

Isso é evidente, uma vez que dados da (Rede Globo, 2020), citados acima neste artigo, comprovam que reality shows são um sucesso de audiência. Em 2021, o programa segue com o mesmo êxito, a emissora divulgou em alguns episódios em que o programa estava ao vivo (principalmente nos dias de eliminação, às terças-feiras), entre Janeiro e Maio de 2021, que houveram dias em que foram estabelecidos recordes de votos por minuto ou de porcentagens de votação (tanto de rejeição, quanto de aceitação de participantes).

\subsection{Marketing pessoal}

O conceito de marketing pessoal se trata de uma subdivisão do marketing que tem como núcleo a pessoa. Segundo Rein et al (2006, p. 42), o marketing pessoal como também sua promoção pode ser compreendido como:

O sistema é orientado para o público e características potenciais do aspirante, o conceito e história da marca do aspirante são refinados e posicionados para o mercado (proposta de valor), e o vestuário, aparência e comportamento (frequentemente referido como identidade estendida) são concebidos para reforçar o papel e tipo do aspirante". Pode ser observado que o foco da definição de Kotler é de uma maneira mais acadêmica e mercadológica, podendo ser compreendido que o ser humano se torna o estudo e objeto de pesquisa do marketing pessoal.

Outra definição proposta por Silva, et al. (2019, p.10), define o marketing pessoal como:

Uma necessidade para muitos, já que por meio dele é possível criar uma imagem de si que possa potencializar os pontos fortes e diminuir os fracos, além disso uma boa imagem transmite confiança e credibilidade que são elementos chave para se destacar no mercado ou dentro de uma empresa.

Pode ser compreendido por meio das duas definições que o marketing pessoal se trata do conceito de vender uma imagem, podendo se tratar de sua carreira, vida pessoal, atributos, características e demais características do ser. A autora (Jacobson, 2020) complementa informando que a marca pessoal é representada de forma consciente e subconsciente pelo indivíduo, com o uso das redes sociais a informação é combinada e apresentada por meio de um sistema de troca de informação, assim criando uma identidade e consumida pelo seu público respectivamente.

Albuquerque \& Costa (2020, p. 164), estabelecem a concepção de que: "marketing pessoal é uma estratégia utilizada na promoção pessoal com o objetivo de alcançar o sucesso por meio da "venda" da própria imagem, criando uma identidade específica no mercado". Sendo assim, surge a necessidade de se elaborar um plano de marketing bem desenvolvido, pois no seu ambiente, seja no mercado de trabalho ou em outro, a pessoa competirá o seu marketing pessoal com a de tantos outros concorrentes.

\subsection{Marketing digital}

Trata-se do marketing online, que surgiu como desdobramento natural, devido à interação dos consumidores com o meio digital. Atualmente, o Marketing Digital assumiu grande importância para os negócios, mas ele não deve ser entendido como uma evolução do Marketing Tradicional, que vem a substituir os conceitos de seu antecessor, mas sim contribuir para um atendimento mais completo para a realidade dos consumidores atuais. (Kotler, 2017). 
A grande importância do Marketing Digital é a promoção de ações e a defesa da marca, uma vez que com a relação contínua do consumidor com a marca, os clientes passam a exigir um relacionamento mais próximo a ela e essa exigência pode ser melhor contemplada com a utilização do Marketing Digital. E o marketing online é diferente do offline, porque diferente das funções do Marketing Digital, o Marketing Tradicional tem suas vantagens, principalmente no quesito de iniciar o relacionamento com o cliente e as estratégias iniciais para as marcas, como por exemplo, acontecem quando se desenvolvem as estratégias sobre 4 P's (Preço, Praça, Promoção e Produto) (Kotler, 2017).

Com isso, as teorias acerca do Marketing Digital serão de grande valia para esse trabalho, uma vez que possibilitam um melhor relacionamento das marcas, no caso, as personalidades com o público em geral. Uma das mais importantes funções do Marketing Digital é levar o consumidor da assimilação à ação, ou seja, converter a propaganda em mais resultados. Os autores (Umami \& Darma, 2021) também ressaltam a importância do apoio e promoção paga para a promoção de uma marca nas redes sociais, que aumenta o reconhecimento da marca e consequentemente o interesse na compra.

O uso das ferramentas de Marketing Digital que são utilizadas não devem ser exclusivas, na verdade, deve-se usá-las combinadas para maiores resultados. (Kotler, 2017).

\subsection{Co-marketing}

Segundo (Bucklin \& Sengupta, 1993), co-marketing é uma forma de colaboração entre empresas, na qual elas contribuem para o sucesso mútuo, permitem a expansão de habilidades e alcançam novos mercados. Ou seja, o co-marketing atua em forma de parcerias, considerando que duas ou mais partes se unem em prol de maximizar o alcance de um projeto, produto ou serviço. (Fernandes, 2017) acrescenta que para que ocorram, as empresas não devem ser concorrentes, assim proporcionando um maior alcance em um menor período, gerando menos custo pelo fortalecimento das marcas participantes.

Quando trabalham juntas em iniciativas de co-marketing, as empresas são mutuamente beneficiadas, considerando que o produto alcança mais pessoas ao compilar clientes de todos os envolvidos. Desse modo, os lucros tendem a ser maximizados em decorrência do aumento de vendas.

É comum que participantes de reality show sejam patrocinados por grandes marcas para promover produtos ou serviços que tenham relação com sua personalidade. É importante que haja uma afinidade entre as partes envolvidas, para que ambos os públicos se interessem pelo conteúdo e exista um impulso real de vendas como consequência da parceria.

É vantajoso que grandes empresas associem as pessoas certas à sua marca, inclusive participantes de reality show. Estes possuem o apoio do público e adquirem alto poder de influência após serem expostos nos programas televisivos, o que demonstra uma oportunidade para concretização de trabalhos de co-marketing.

\section{Metodologia}

A metodologia deste trabalho foi elaborada levando em consideração os estudos já realizados na literatura da área, que contivessem em si algum, ou mais de um, temas que incluem: Marketing Digital, Marketing Pessoal, Co-Marketing e mídias digitais. Para isso, foi realizada, previamente, uma pesquisa bibliográfica, que possibilitou a composição desta metodologia de caráter quali-quantitativo. Contudo, as metodologias escolhidas para esse artigo são: Análise de Conteúdo, Discurso do Sujeito Coletivo e Análise Descritiva.

\subsection{Análise de conteúdo}

Compreendendo que é necessário o conhecimento de um especialista na área a fim de elucidar o pensamento estratégico e ações dos participantes dentro e fora (mídias sociais) do reality, foi decidido pela realização de uma entrevista utilizando como metodologia a análise de conteúdo. 
A escolha desta metodologia se dá pela sua fundamentação na extração das estratégias envolvidas nas ações, assim como os autores Silva e Fossá a definem: "uma técnica de análise das comunicações, que irá analisar o que foi dito nas entrevistas ou observado pelo pesquisador. Na análise do material, busca-se classificá-los em temas ou categorias que auxiliam na compreensão do que está por trás dos discursos" (Silva \& Fossá, 2015, p. 2).

Já a autora Bardin (1977, p. 42) demonstra que os indicadores gerados pela análise de conteúdo não são limitados a quantitativos, definindo a metodologia em questão como:

um conjunto de técnicas de análise das comunicações visando a obter, por procedimentos sistemáticos e objetivos de descrição do conteúdo das mensagens, indicadores (quantitativos ou não) que permitam a inferência de conhecimentos relativos às condições de produção/recepção (variáveis inferidas) destas mensagens.

Pode então ser concluído que a análise de conteúdo tem como principal objetivo compreender a real mensagem emitida pelo entrevistado, no caso de entrevistas. Além disso, também classifica e categoriza o conteúdo da fala do emissor, auxiliando a análise completa e minuciosa do discurso, fornecendo um ponto de vista profissional essencial ao que deve ser analisado em determinado assunto.

Neste trabalho, para compreender a criação e gestão da marca do participante, foi realizada uma entrevista com um profissional do ramo do Marketing Digital aplicado ao Marketing Pessoal.

Esta pessoa foi membro de uma agência de estratégia de Marketing Digital muito relevante no Brasil, a qual é responsável pelo gerenciamento de redes sociais e criação de planos estratégicos de vários famosos brasileiros. Nesta agência, o entrevistado trabalhou indiretamente com a gestão das redes sociais de Karol Conká durante o programa BBB 21 e, também, tratou indiretamente da estratégia de lançamento do EP de Juliette. E, mais do que isso, acompanhou integralmente o BBB 21, sendo capaz de dividir suas percepções sobre a gestão dos perfis de Juliette, Karol Conká e Gil.

A fim de realizar a análise de conteúdo da entrevista, seguiu-se as orientações de Bardin em "Análise de Conteúdo":

As diferentes fases da análise de conteúdo, tal como o inquérito sociológico ou a experimentação, organizam-se em torno de três polos cronológicos: 1) a pré-análise; 2) a exploração do material; 3) o tratamento dos resultados, a inferência e a interpretação. (Bardin, 1977, p. 95)

Na etapa de pré-análise foi feita a organização dos conteúdos disponíveis, sendo definida a entrevista como o único material submetido à análise. Em segundo lugar, foi feita a codificação da entrevista, etapa na qual decidiu-se analisar somente as falas referentes a Juliette, Gil e Karol Conká, desconsiderando comentários e análises da estratégia de outros participantes do BBB 21 que não estão no escopo deste trabalho. A terceira etapa, de resultados, inferências e interpretações, será apresentada na seção de Análise de Resultados.

É importante salientar que a escolha dos três participantes da edição do BBB 2021 foi feita de acordo com a relevância que obtiveram no reality, tendo como objetivo estudar as diferentes práticas e estratégias de marketing pessoal utilizadas em suas redes sociais. Juliette foi vencedora da edição, tendo sido escolhida pelo público e conquistado um grande número de parcerias pós reality; Gil não venceu o reality, mas obteve inúmeras parcerias e fãs; e Karol Conká, que obteve repercussões negativas durante sua participação, mas tem conseguido reduzir os danos de sua imagem.

\subsection{Discurso do sujeito coletivo (DSC)}

Para ter uma análise dos resultados e dos fundamentos das estratégias utilizadas para a gestão da marca do participante, vê-se necessária a observação do seu público. Pensando nisso, foi escolhida a metodologia do Discurso do 
Sujeito Coletivo (DSC) visando à sintetização de uma opinião coletiva, realizando uma pesquisa qualitativa para considerar nuances como crenças, valores e aspirações das pessoas que são relacionadas ao participante. Além disso, o DSC busca apresentar um discurso na primeira pessoa para reforçar a importância das opiniões, uma vez que o discurso na primeira pessoa é aquele que é usual e mais eficiente para expressar para o outro que aquela opinião foi gerada em seu cérebro.

[...] na primeira pessoa do singular, é o regime natural de funcionamento das opiniões ou representações sociais. De fato, as opiniões ou representações sociais são eficientes, funcionam, justamente, porque os indivíduos acreditam que suas opiniões são suas, ou seja, geradas em seus cérebros. (Lefevre \& Lefevre, 2006, p.519)

Para consolidar a metodologia neste trabalho, foi utilizado como base o artigo "O Instagram como estratégia de marketing: um estudo na empresa Chocolates Garoto" (Piccioli, et al., 2021), que aplicou o DSC para analisar a comunicação da marca, com foco nas suas redes sociais. Também foi utilizado o artigo "O sujeito coletivo que fala" (Lefevre \& Lefevre, 2006), como fundamento na análise prática.

A metodologia do Discurso do Sujeito Coletivo propõe a utilização de quatro elementos a serem analisados, conforme expressado por (Figueiredo, 2013). O Quadro 1 detalha os quatro elementos do discurso do sujeito coletivo:

Quadro 1 - Quatro elementos DSC.

\begin{tabular}{|l|l|}
\hline \multicolumn{1}{|c|}{ Tipo } & \multicolumn{1}{|c|}{ Definição } \\
\hline $\begin{array}{l}\text { Expressões chave } \\
\text { (ECH) }\end{array}$ & $\begin{array}{l}\text { São pedaços, trechos do discurso, que devem ser destacados pelo pesquisador, e que revelam a } \\
\text { essência do conteúdo do discurso ou a teoria subjacente. }\end{array}$ \\
\hline Idéia Central (IC) & $\begin{array}{l}\text { é um nome ou expressão lingüística que revela, descreve e nomeia, da maneira mais sintética e } \\
\text { precisa possível, o(s) sentido (s) presentes em cada uma das respostas analisadas e de cada conjunto } \\
\text { homogêneo de ECH, que vai dar nascimento, posteriormente, ao DSC. }\end{array}$ \\
\hline Ancoragem (AC) & $\begin{array}{l}\text { algumas ECH remetem não apenas a uma IC correspondente, mas também e explicitamente a uma } \\
\text { afirmação que denominamos Ancoragem (AC) que é a expressão de uma dada teoria ou ideologia } \\
\text { que o autor do discurso professa e que está embutida no seu discurso como se fosse uma afirmação } \\
\text { qualquer. }\end{array}$ \\
\hline $\begin{array}{l}\text { Discurso do Sujeito } \\
\text { Coletivo (DSC) }\end{array}$ & $\begin{array}{l}\text { É uma reunião num só discurso-síntese redigido na primeira pessoa do singular de ECH que têm ICs } \\
\text { ou Acs semelhantes ou complementares. }\end{array}$ \\
\hline
\end{tabular}

Fonte: Adaptado de Figueiredo (2013).

Seguindo a metodologia de Figueiredo, neste trabalho identificou-se o Discurso do Sujeito Coletivo em relação às personalidades do escopo: Juliette, Gil e Karol Conká. Para isso, as redes sociais Instagram e Twitter foram selecionadas como fonte de comentários para criar um DSC que representasse a opinião do público em relação aos participantes.

Para a aplicação da metodologia, conforme ilustrado no Quadro 2, foram consideradas duas contas diferentes: a conta oficial dos participantes (Instagram e Twitter) e a conta oficial do BBB no Twitter. A partir dessas fontes, foram avaliados os conteúdos divulgados em três períodos diferentes: entre novembro e dezembro de 2020; durante a permanência do participante no BBB; e entre agosto e setembro de 2021. Esta divisão baseia-se na justificativa de que era esperado visualizar um impacto claro na interação entre participante e seguidores das redes sociais em decorrência da participação no BBB.

Para o Instagram, a pesquisa foi constituída selecionando as duas postagens mais curtidas em cada semana dos períodos estipulados. Depois da seleção, foram coletados os 10 comentários mais relevantes na semana das postagens. 
Para o Twitter, foram selecionados os dois tweets mais curtidos de cada semana analisada em dois perfis para cada participante, incluindo o perfil oficial do participante (@gildovigor, @juliette e @karolconka) e as citações dos participantes no perfil oficial do BBB (@ bbb); após a seleção dos tweets, coletou-se 10 comentários do dia.

$\mathrm{Na}$ Análise de Resultados, serão evidenciadas as categorizações dos comentários coletados durante a pesquisa a fim de justificar, com dados numéricos, a construção do DSC realizada pela equipe.

Para a constituição do DSC, que será apresentado na Análise de Resultados, foram feitos discursos diferentes para possibilitar a comparação entre períodos e fontes. Os discursos foram divididos da seguinte maneira:

Quadro 2 - Períodos e plataformas analisadas.

\begin{tabular}{|l|l|l|}
\hline \multicolumn{1}{|c|}{ Período } & \multicolumn{1}{c|}{ Rede Social } & \multicolumn{1}{c|}{ Conta } \\
\hline Novembro a Dezembro de 2020 & Instagram e Twitter (se aplicável)* & Conta oficial do participante \\
\hline Tempo de permanência no BBB & Instagram e Twitter & $\begin{array}{l}\text { Conta oficial do participante } \\
\text { Conta oficial do BBB (apenas Twitter) }\end{array}$ \\
\hline Agosto a Setembro de 2021 & Instagram e Twitter & Conta oficial do participante \\
\hline
\end{tabular}

* A construção do Discurso do Sujeito Coletivo para o período de 11/2020 a 12/2020 não foi realizada para Gil porque ele não utilizava as redes sociais no período; no caso de Juliette, foi utilizado apenas o Instagram, pois o Twitter ainda não era utilizado; apenas Karol Conká já utilizava as duas redes sociais no período. Fonte: Autores

\subsection{Análise descritiva}

Para se ter uma análise dos resultados proporcionados pelo programa ao participante, foram utilizadas suas redes sociais como fonte de dados, sendo necessária uma metodologia que proporciona formas de analisar os detalhes mais relevantes. Foi então escolhida a Análise Descritiva, visto que: "Utilizamos métodos de Estatística Descritiva para organizar, resumir e descrever os aspectos importantes de um conjunto de características observadas ou comparar tais características entre dois ou mais conjuntos." (Reis \& Reis, 2002, p. 5).

As análises dos participantes foram efetuadas em relação ao número de parcerias e à evolução no número de seguidores nas redes sociais. Como parceria, entende-se toda relação entre o participante e outras pessoas/marcas que beneficie ambas as partes. Considera-se neste trabalho as parcerias divididas em três tipos: marcas, influencers e produtos, sendo os produtos, propaganda de produção própria dos participantes.

Para a análise de parcerias foi analisada a conta do Instagram dos participantes, quantificando os parceiros e a quantidade de publicações efetuadas para os mesmos. Esta rede social foi utilizada considerando que um de seus objetivos é realizar a promoção de produtos e serviços para facilitar a disseminação entre os seus usuários. Em contrapartida, o Twitter é uma rede social voltada à expressão entre os usuários.

Para a análise dos seguidores, foram utilizadas duas fontes de dados, sendo Trends Map para os dados do Twitter e Desbrava Data para os dados do Instagram. A data delimitada foi do início do BBB até o início de outubro.

\section{Resultados e Discussão}

\subsection{Análise de conteúdo}

A Análise de Conteúdo deste trabalho teve como foco registrar a percepção de um profissional da área com relação às estratégias utilizadas pelos participantes do reality show e seus gestores de imagem. Com o objetivo de captar fidedignamente 
a mensagem do entrevistado, foram realizadas as etapas de pré-análise, sendo a organização de conteúdos previamente à entrevista; a de categorização (Quadro 3), registrando os os eixos temáticos observados no discurso do emissor, separados nas categorias Juliette, Gil, Karol Conká e Gerais; e a de resultados, inferências e interpretações.

Quadro 3 - Eixos temáticos.

\begin{tabular}{|c|c|c|}
\hline $\begin{array}{l}\text { Categorias de } \\
\text { Análise }\end{array}$ & & Eixos Temáticos \\
\hline \multirow[t]{5}{*}{ 1. Juliette } & a. & Estratégia utilizada nas mídias sociais durante o BBB 21 \\
\hline & b. & Exploração da identidade com o público nordestino \\
\hline & c. & O papel dos administradores das redes sociais \\
\hline & d. & O papel do fandom na repercussão de Juliette como um fenômeno \\
\hline & e. & A preparação antes de iniciar o programa BBB 21 \\
\hline \multirow[t]{5}{*}{ 2. Gil } & a. & Estratégia utilizada nas mídias sociais durante o BBB 21 \\
\hline & b. & Criação de uma identidade sólida com o público com base na origem e profissão \\
\hline & c. & Adaptabilidade e bom aproveitamento das circunstâncias durante o BBB 21 \\
\hline & d. & A importância do gerenciamento de mídias sociais por uma agência especializada \\
\hline & e. & A preparação antes de iniciar o programa BBB 21 \\
\hline \multirow[t]{5}{*}{ 3. Karol Conká } & a. & Estratégia utilizada nas mídias sociais durante o BBB 21 \\
\hline & b. & $\begin{array}{l}\text { Estratégias para reforçar a autenticidade que já existia antes do BBB } 21 \\
\text { e recuperar a imagem }\end{array}$ \\
\hline & c. & A utilização de memes/humor na gestão de crise e justificativa das ações \\
\hline & d. & A utilização de duas agências diferentes na gestão das redes sociais \\
\hline & e. & A preparação antes de iniciar o programa BBB 21 \\
\hline \multirow{5}{*}{ 4. Geral } & a. & O perfil dos administradores das redes sociais \\
\hline & b. & O maior desafio dos administradores das redes sociais \\
\hline & c. & Como manter resultados prolongados a partir de situações com alta repercussão \\
\hline & d. & A inovação provocada pelo BBB \\
\hline & e. & A estratégia mais adequada pré, durante e pós BBB na visão do especialista \\
\hline
\end{tabular}

Fonte: Autores (2021).

\section{1. $\underline{\text { Juliette }}$}

$\mathrm{Na}$ primeira categoria de análise, serão analisadas as falas referentes à performance de Juliette no BBB 21, considerando os eixos temáticos abordados na entrevista, sendo eles: 


\section{a. Estratégia utilizada nas mídias sociais durante o BBB 21}

Segundo o entrevistado, Juliette optou por confiar o gerenciamento de suas redes sociais nas mãos de pessoas que já a conheciam antes do reality show. Além de já serem próximos de Juliette, os administradores das redes sociais também eram profissionais de Marketing, o que foi uma ótima combinação para mostrar sua verdadeira identidade ao público e explorar as reações da melhor forma, consolidando uma base sólida de apoiadores. Uma das principais estratégias das mídias sociais foi a postagem de conteúdos relacionados às características principais da participante, sendo elas: advogada, maquiadora e nordestina.

Para o entrevistado, o ponto mais positivo da estratégia utilizada deve-se à excelente adaptabilidade dos administradores em relação ao contexto, sabendo aproveitar momentos de alta repercussão e sabendo lidar com momentos de crítica. Para a gestão de crise, os gestores das redes sociais utilizaram a técnica do storytelling, sempre relembrando ao público quem era a verdadeira Juliette em sobreposição à crise enfrentada. No entanto, um ponto negativo seria a alta confiança dada ao fandom, ou seja, à organização de fãs, de Juliette (ver tópico d).

\section{b. Exploração da identidade com o público nordestino}

No início do BBB 21, Juliette foi apresentada como advogada e maquiadora natural de Campina Grande, Paraíba. Mesmo com todas essas características, foi a origem do Nordeste que mais gerou identidade com o público. Muitos comentaram nas redes sociais que apoiariam Juliette por se sentirem representados como nordestinos. Os administradores aproveitaram muito bem esta repercussão e criaram a identidade visual e apelativa de Juliette em volta do Nordeste. Embora pudessem ter optado por conquistar o apoio do público, "mulheres advogadas", por exemplo, decidiram focar na naturalidade de Juliette.

\section{c. O papel dos administradores das redes sociais}

No caso de Juliette, a paraibana escolheu amigos próximos e, simultaneamente, profissionais de Marketing para gerenciar suas redes sociais. Mas, além de conhecer verdadeiramente a participante e, por isso, conseguirem passar sua verdadeira identidade ao público, os administradores também souberam criar um vínculo forte com os apoiadores e se adaptar de acordo com a situação vigente (ver tópico a).

\section{d. O papel do fandom na repercussão de Juliette como um fenômeno}

Um dos principais fatores de sucesso para o BBB 21 é possuir uma base sólida de apoiadores. No caso de Juliette, ela conquistou milhões de fãs durante a participação no reality, o que foi essencial para organizar mutirões de votação e levá-la à vitória. No entanto, o entrevistado aponta que os administradores deram muita confiança ao fandom, o que acabou impactando a estratégia negativamente. Os fãs demonstraram apoio assíduo à nordestina, e muitos foram intolerantes a quaisquer opiniões contrárias à Juliette nas redes sociais, o que gerou uma repercussão negativa. Houve uma defesa absoluta das atitudes e comportamentos de Juliette, mesmo quando ela foi altamente criticada, gerando polêmicas nas mídias sociais.

\section{e. A preparação antes de iniciar o programa BBB 21}

A principal preparação de Juliette antes do BBB 21 está relacionada a escolher o responsável por representá-la nas redes sociais durante o reality show; tirar fotos para postar durante o BBB 21; e produzir conteúdos para serem utilizados também durante o programa. 


\section{2. $\underline{\text { Gil }}$}

Na segunda categoria de análise, serão analisadas as falas referentes à performance de Gil no BBB 21, considerando os eixos temáticos abordados na entrevista, sendo eles:

\section{a. Estratégia utilizada nas mídias sociais durante o BBB 21}

É provável que Gil não tenha desenvolvido uma estratégia clara antes de iniciar no reality show. No início, suas redes sociais eram gerenciadas por amigos; durante o programa, uma assessoria passou a administrar suas mídias, o que foi positivo, porque as publicações passaram a ser mais direcionadas, e negativo, porque iniciou tardiamente.

Mesmo assim, os administradores das redes sociais souberam se adaptar e aproveitar as oportunidades e, ao mesmo tempo, fazer bom uso de desenhos e artes, proporcionados por parcerias com artistas. Além disso, a identidade de Gil ficou bem marcada, o que é reflexo do direcionamento dos conteúdos criados pelos gestores das redes sociais.

\section{b. Criação de uma identidade sólida com o público com base na origem e profissão}

Para construir uma boa rede de apoiadores, é essencial que o participante denote características que reforçam sua identidade com o público. No caso de Gil, a origem nordestina e a profissão de economista foram os atributos principais. Por isso, os conteúdos foram direcionados para reforçar essa identidade e criar uma solidez em sua imagem, para que ele fosse associado às características de nordestino e economista e ser lembrado por elas.

\section{c. Adaptabilidade e bom aproveitamento das circunstâncias durante o BBB 21}

Embora Gil não tivesse uma estratégia definida ao entrar no programa, os administradores de suas redes foram muito bons em "dançar conforme a música"; eles aproveitaram os momentos de boa repercussão para gerar engajamentos e parcerias e se adaptaram às oportunidades emergentes.

\section{d. A importância do gerenciamento de mídias sociais por uma agência especializada}

Conforme citado no tópico a, a administração das redes sociais de Gil iniciou sob os cuidados de amigos próximos e, depois, migrou para uma assessoria especializada. Isso demonstra que, dada a magnitude do BBB 21, é importante contratar profissionais de Marketing para traçar boas estratégias de marketing digital e aumentar o engajamento do perfil, levando a melhores resultados em termos financeiros e consolidação de imagem.

\section{e. A preparação antes de iniciar o programa BBB 21}

Ao que parece, as duas preparações de Gil antes do BBB foram: direcionar suas redes sociais para amigos e tirar fotos para conteúdos futuros. Como mencionado anteriormente, no início não parecia haver uma estratégia traçada para ser utilizada durante o programa.

\section{3. $\underline{\text { Karol Conká }}$}

$\mathrm{Na}$ terceira categoria de análise, serão analisadas as falas referentes à performance de Karol Conká no BBB 21, considerando os eixos temáticos abordados na entrevista, sendo eles:

\section{a. Estratégia utilizada nas mídias sociais durante o BBB 21}

O caso de Karol Conká é o mais curioso entre os três participantes analisados. Durante o BBB 21, todas as publicações foram apagadas. Isso aconteceu devido às grandes críticas que Karol sofreu na "vida real" em decorrência de seu comportamento no programa. 
Diante da grande crise instaurada durante sua participação, havia duas agências de marketing responsáveis pela gestão das redes sociais. No entanto, as agências não concordavam em qual estratégia seguir para remediar a situação e, por isso, a decisão foi manter o silêncio e apagar as publicações do período.

No início do BBB 21, antes das polêmicas negativas envolvendo Karol Conká, não havia uma estratégia definida para a participação no programa. A falta de estratégia específica ocorreu por dois motivos: i) considerando que a cantora já era uma personalidade pública antes do reality, foi mantida a mesma interação de antes com os seguidores; e ii) a agência foi informada sobre a participação no programa dias antes do início do BBB, o que impediu tempo hábil para criar uma estratégia e gerar conteúdos alinhados com a mesma.

\section{b. Estratégias para reforçar a autenticidade que já existia antes do BBB 21 e recuperar a imagem}

É sabido que o comportamento de Karol Conká durante o programa teve uma péssima aceitação do público. As pessoas repudiaram suas ações e a sua credibilidade como figura pública foi muito comprometida, levando a perda de seguidores, parcerias e shows que já estavam agendados.

Para reverter a deterioração da imagem da cantora, a estratégia foi relembrar quem ela era antes de entrar no BBB 21. Não houve intenção de criar uma "nova Karol”, ou “evangelizar" sua imagem, colocando-a na posição de redentora. O objetivo foi reforçar a autenticidade que a cantora sempre demonstrou, e retomar sua aceitação e credibilidade.

Para isso, foi passada a mesma mensagem de diferentes maneiras, buscando o alcance do maior público possível e retenção dos fãs. Além disso, buscou-se participar de programas televisivos e fazer parcerias com marcas que possuíam credibilidade no momento.

\section{c. A utilização de memes/humor na gestão de crise e justificativa das ações}

Durante situações desfavoráveis e alvo de críticas, o ideal é assumir o erro. A autocrítica é fundamental na gestão de crise, alinhada ao trabalho de transformar o tom da situação. Uma boa alternativa é tratar a situação com memes e utilizá-los para convencer o público de que a pessoa não se resume ao erro que cometeu. Outra alternativa é utilizar a técnica do storytelling para, mais uma vez, lembrar o público da verdadeira identidade do participante, reforçando os pontos positivos e os pontos de identidade com a rede de apoio.

Quanto ao comportamento desempenhado por Karol, que foi reprovado pelo público, o profissional entrevistado justificou: a cantora sentia muita pressão dentro do BBB 21, não apenas por ter que lidar com a expectativa do público, que já a conhecia, mas também por consequências de fatores externos, como o fato de ser artista na pandemia e, de repente, mudar bruscamente a rotina de fazer shows e conviver com fãs. Estes aspectos tiveram um impacto no comportamento da cantora.

\section{d. A utilização de duas agências diferentes na gestão das redes sociais}

Um dos pontos negativos da estratégia escolhida por Karol Conká foi a contratação de duas agências para assessorá-la na gestão de suas redes sociais. A falta de consenso foi notória durante a gestão de crise com a qual não lidaram devido a discordâncias entre as contratadas. Durante o programa, todas as publicações foram apagadas e não houve uma estratégia predominante para reconstruir a imagem de Karol Conká. Embora seja importante contar com apoio profissional, é importante centralizar a tutela pelo Marketing Digital e alinhar previamente as expectativas em relação a papéis e responsabilidades.

\section{e. A preparação antes de iniciar o programa BBB 21}

Antes do BBB 21, Karol preparou conteúdos para serem utilizados durante o programa. Porém, a preparação não foi acompanhada pela agência responsável por suas redes sociais. Por isso, o conteúdo não pôde ser utilizado, já que não estava alinhado com nenhuma estratégia e não se mostrou apropriado para ser utilizado durante a situação de crise. 
Quanto à escolha dos administradores de sua conta, também não houve um alinhamento, o que levou aos impasses abordados no tópico $\mathbf{d}$.

\section{Geral}

$\mathrm{Na}$ quarta categoria de análise, serão analisadas as falas referentes a temas gerais que envolvem os três participantes do escopo, considerando os eixos temáticos abordados na entrevista, sendo eles:

\section{a. $\mathrm{O}$ perfil dos administradores das redes sociais}

Todos os casos estudados precisam de administradores que, além de especialistas em Marketing, sejam ativos nas redes sociais e mantenham contato com o público, organizando mutirões e criando um vínculo sólido com a rede de apoio do participante.

Além de ser presente nas mídias, o administrador precisa ser sensível às reações do público e aproveitar as oportunidades para promover o perfil do participante. E, por fim, ele deve conhecer profundamente o participante, entrando na linguagem e no "tom" da personalidade, a fim de demonstrar ainda mais proximidade com os fãs.

\section{b. O maior desafio dos administradores das redes sociais}

O maior desafio dos administradores das redes sociais é estabelecer uma base sólida de apoiadores. O sucesso do participante está muito ligado a quanto ele consegue conquistar o suporte e a confiança do público. Além disso, há outros desafios relevantes para o administrador, sendo eles: i.) conhecer as particularidades do participante; ii.) gerar conteúdo para as redes sociais; iii.) conhecer seu público e mantê-lo fiel; e iv.) explorar as oportunidades de engajamento vigentes, mas sempre pensando nos próximos passos.

\section{c. Como manter resultados prolongados a partir de situações com alta repercussão}

É necessário realizar um planejamento estratégico para se alinhar às expectativas do público, fonte do engajamento que gera repercussão. Para isso, é importante fazer o mapeamento do público, o que permite compreender do que os seguidores mais gostam e direcionar conteúdos a partir das métricas geradas nas redes sociais.

Além disso, é recomendável utilizar os memes até a exaustão e saber utilizar todas as oportunidades que surgirem, como parcerias. Neste caso, geralmente a proposta parte da marca para o participante, mas é possível iniciar a proposta de maneira ativa, partindo do participante para a marca. Para isso, recomenda-se enviar um media kit com as métricas e informações sobre o público. Para selecionar as parcerias, é necessário verificar se os públicos combinam e confiar no feeling (know how), pois as consequências não são conhecidas.

\section{d. A inovação provocada pelo BBB}

Segundo o entrevistado, a maior inovação provocada pelo reality show está ligada ao fato de que ele representa um multiplicador jamais visto antes. Tudo o que passa pelo BBB tem proporções maiores do que poderia alcançar sozinho. Ou seja, tudo o que é bom fica melhor, e tudo o que é ruim fica pior. Portanto, a inovação está na característica amplificadora das ações quando estas estão ligadas ao programa. A repercussão de todas as atitudes é muito maior do que seria caso estivesse em outro contexto. 


\section{e. A estratégia mais adequada pré, durante e pós BBB na visão do especialista}

Com o objetivo de facilitar a compreensão da estratégia ideal pré, durante e pós BBB, foi feito o seguinte Quadro 4, ilustrando a percepção do entrevistado.

Quadro 4 - Estratégias.

\begin{tabular}{|c|c|c|}
\hline Pré-BBB & Durante BBB & Pós BBB \\
\hline $\begin{array}{c}\text { Fazer terapia para o autoconhecimento e } \\
\text { manter a saúde mental e equilíbrio }\end{array}$ & $\begin{array}{c}\text { Criar uma rede forte de apoio ao } \\
\text { participante, mantendo contato ativo com } \\
\text { o público }\end{array}$ & $\begin{array}{c}\text { Explorar a identidade sólida desenvolvida } \\
\text { durante o programa }\end{array}$ \\
\hline $\begin{array}{c}\text { Escolher o administrador responsável pelas } \\
\text { redes sociais com o perfil citado no tópico a }\end{array}$ & $\begin{array}{c}\text { Estabelecer uma identidade como marca } \\
\text { sólida do participante }\end{array}$ & $\begin{array}{c}\text { Manter contato ativo com o público } \\
\text { conquistado durante o programa }\end{array}$ \\
\hline $\begin{array}{c}\text { Compartilhar com o administrador os } \\
\text { pontos fortes, fracos e a linguagem pessoal } \\
\text { do participante }\end{array}$ & $\begin{array}{c}\text { Focar em demonstrar os pontos fortes do } \\
\text { participante, mesmo em momentos de } \\
\text { crise }\end{array}$ & $\begin{array}{c}\text { Procurar oportunidades em outros públicos, } \\
\text { mas manter o foco na rede de apoio construída } \\
\text { no BBB }\end{array}$ \\
\hline $\begin{array}{c}\text { Preparar conteúdos falando sobre assuntos } \\
\text { diversos, mas mantendo foco em seu } \\
\text { nicho/público com quem tem identidade }\end{array}$ & $\begin{array}{c}\text { Aproveitar todas as oportunidades que } \\
\text { surgirem, inclusive de parcerias que } \\
\text { tenham identificação do público }\end{array}$ & $\begin{array}{c}\text { Aproveitar oportunidades que estejam ligadas } \\
\text { àdentidade do participante, como parcerias }\end{array}$ \\
\hline $\begin{array}{c}\text { Preparar-se fisicamente para as provas de } \\
\text { resistência }\end{array}$ & $\begin{array}{c}\text { Manter a linguagem do participante como } \\
\text { uma persona }\end{array}$ & $\begin{array}{c}\text { Continuar com o apoio de uma assessoria } \\
\text { especializada em Marketing Digital }\end{array}$ \\
\hline
\end{tabular}

Fonte: Autores (2021).

\subsection{Discurso do sujeito coletivo}

Conforme o tópico Metodologia, a partir dos comentários coletados e de sua categorização, construiu-se o Discurso do Sujeito Coletivo, que visa a mostrar a opinião do público referente a cada um dos participantes no período estipulado:

\subsubsection{Juliette}

\subsubsection{Categorização}

Ao realizar a consolidação das categorizações dos comentários nas contas relacionadas à Juliette, como descrito na metodologia, foi constatado que no período Pré-BBB (Novembro e Dezembro de 2020) 96\% dos comentários eram de elogios à imagem do participante.

No período do programa, liderando o ranking com $20 \%$ do total, estão os comentários de alusão a outros participantes e, por fim, após o BBB, com 59\% do número de comentários estão no topo, novamente, comentários de elogios à imagem do participante.

O Quadro 5, compila os dados apurados sobre a participante Juliette: 
Quadro 5 - Categorização dos comentários das contas relacionadas à Juliette.

\begin{tabular}{|c|c|c|c|}
\hline JULIETTE & NOV-DEZ/20 & JAN-MAI/21 & AGO-SET/21 \\
\hline Elogios ao comportamento no BBB & $0 \%$ & $11 \%$ & $0 \%$ \\
\hline Elogios à imagem do participante & $96 \%$ & $19 \%$ & $59 \%$ \\
\hline Críticas ao comportamento no BBB & $0 \%$ & $8 \%$ & $0 \%$ \\
\hline Críticas à imagem do participante & $2 \%$ & $0 \%$ & $1 \%$ \\
\hline Identificação com participante & $0 \%$ & $3 \%$ & $1 \%$ \\
\hline Alusão a outros participantes & $0 \%$ & $20 \%$ & $2 \%$ \\
\hline Alusão a humor (memes) & $2 \%$ & $4 \%$ & $3 \%$ \\
\hline Interesse por produtos utilizados & $0 \%$ & $3 \%$ & $4 \%$ \\
\hline Apoio no BBB & $0 \%$ & $18 \%$ & $0 \%$ \\
\hline Emojis de apoio & $0 \%$ & $8 \%$ & $15 \%$ \\
\hline Apoio à carreira de cantora & $0 \%$ & $0 \%$ & $5 \%$ \\
\hline Crítica à carreira de cantora & $0 \%$ & $0 \%$ & $0 \%$ \\
\hline Outros & $0 \%$ & $6 \%$ & $10 \%$ \\
\hline
\end{tabular}

Fonte: Autores (2021).

\subsubsection{Discurso do sujeito coletivo de cada período}

\section{Discurso do Sujeito Coletivo 1: Novembro a Dezembro de 2020}

A Juliette é perfeita! É uma das amigas mais maravilhosas que eu tenho; as fotos dela não trazem nenhuma novidade: ela é maravilhosa por dentro e por fora, está sempre linda e posa como uma diva. Gata e plena.

\section{Discurso do Sujeito Coletivo 2: Janeiro a Maio de 2021 (conta oficial do participante)}

Juliette é nordestina, vem de Campina Grande. Essa me representa! Antes mesmo do início do programa, eu já estava na torcida. Eu tinha certeza de que ela iria nos representar muito bem. O Brasil e o Nordeste sempre estiveram com Juliette porque ela merecia ser a campeã desse programa. Durante o BBB, ela mostrou a rainha que é, uma lenda! Eu sempre achei incrível como ela foi verdadeira; mostrou ter beleza por dentro e por fora. Sempre indicou que seria a vencedora do programa e roubou meu coração logo nos primeiros dias.

Foi demais quando ela formou o trio G3 com o Gil e a Sarah. Eles foram incríveis juntos! E também foi muito bem empregado quando Juliette falou que a Karol era apenas um ser humano, derrubando toda a exaltação que faziam a ela por ser famosa. Ela falou o que o público queria ouvir lá dentro, porque ninguém aguentava mais a Karol com aquelas péssimas atitudes. Foi por isso que Juliette voltou do paredão e ficou até a final! Ela demonstrou que além de linda, é muito sincera e forte. Provou que é pau!!! 
Até hoje eu volto nas publicações de seu Instagram para reviver o momento em que anunciaram sua vitória. Me emociono! As lágrimas dela são verdadeiras e é muito tocante. Ela é merecedora de tudo o que conquistou. O que nós, fãs, sentimos é um amor verdadeiro.

\section{Discurso do Sujeito Coletivo 3: Janeiro a Maio de 2021 (conta oficial do BBB)}

Logo que a Juliette entrou no programa, ela era muito chata! Passava muita vergonha em rede nacional porque sempre ficava em cima do Fiuk, mesmo que todos percebessem que ele não queria papo com ela. Mas, depois, ela teve alguns comportamentos notáveis, quando disse, por exemplo, que queria jogar o jogo, e não com a vida das pessoas. Isso foi muito importante, porque o ambiente do BBB estava muito tóxico. Ter pessoas que pensavam no próximo era muito importante. Assim ela se tornou protagonista do programa!

O problema é que, com o tempo, eu achei que ela começou a ter um comportamento muito arrogante e autoritário. Até chegar em um nível insuportável, eu diria. Na metade do jogo, Juliette distorcia todos os acontecimentos e sempre se vitimiza! Eu passei a discordar de suas atitudes e a considerá-la muito egocêntrica.

Perto do final do programa, a Juliette voltou a mostrar que tinha um coração bom. Ela teve um desentendimento com o Gil e isso gerou muitas mágoas para os dois, mas pouco tempo depois ela conversou com ele, pediu um abraço e os dois voltaram a se entender. Ela é uma pessoa evoluída e que, mesmo com todos os percalços, isso não muda sua essência. Foi muito bom quando ela, finalmente, ganhou a última prova do líder. Ela chorou de emoção e eu chorei junto. Juliette mereceu ter sido a campeã do programa. Um verdadeiro fenômeno!

\section{Discurso do sujeito coletivo 4: Agosto a Setembro de 2021}

O que dizer de Juliette? Que mulher! Depois que saiu do BBB, conseguiu ficar ainda mais perfeita e poderosa. Comprou casa nova, lançou álbum... Um espetáculo de mulher! E tudo isso ela merece muito!

Juliette sempre está linda, gata e maravilhosa! Eu nunca me canso de dizer o quanto ela é bonita... Além das fotos, outra coisa que eu amo acompanhar são as muitas parcerias que ela fez depois do BBB! Juliette e Alexandre Pires ficaram perfeitos juntos, e eu esperei muito para ver o encontro dela com o Chico César. Meu Deus, foi muito lindo! Também foi muito fofo quando a Ju se encontrou com a Majur! Dá para acreditar que a Juliette é tão pitica que a Majur ergueu ela no colo?

Eu amei acompanhar a trajetória dela durante o BBB e acompanhá-la crescendo. Sempre que assisto ao depoimento de Tiago Leifert na final, eu me emociono muito. Eu sei o quanto essa vitória significou para Juliette e para todos os cactos! A verdade é que ela nunca esteve sozinha e, eu tenho certeza: todos os fãs, inclusive eu, ficarão com ela até o fim!

\subsubsection{Gil}

\subsubsection{Categorização}

A situação das contas de Gil é evidenciada no Quadro 6, sendo possível identificar que, no período Pré-BBB, o participante não teve comentários de nenhuma natureza, uma vez que, não possuía posts desse período.

Já no período do programa, a categoria que lidera o ranking, com $21 \%$ do total de comentários, é a de comentários de alusão a outros participantes, após o BBB, $49 \%$ dos comentários são considerados como comentários de elogios à imagem do participante. 
Quadro 6 - Categorização dos comentários das contas relacionadas ao Gil.

\begin{tabular}{|c|c|c|c|}
\hline GIL & NOV-DEZ/20 & JAN-MAI/21 & AGO-SET/21 \\
\hline Elogios ao comportamento no BBB & - & $14 \%$ & $42 \%$ \\
\hline Elogios à imagem do participante & - & $6 \%$ & $1 \%$ \\
\hline Críticas ao comportamento no BBB & - & $8 \%$ & $0 \%$ \\
\hline Críticas à imagem do participante & - & $6 \%$ & $1 \%$ \\
\hline Identificação com participante & - & $21 \%$ & $10 \%$ \\
\hline Alusão a outros participantes & - & $8 \%$ & $1 \%$ \\
\hline Alusão a humor (memes) & - & $0 \%$ & $22 \%$ \\
\hline Interesse por produtos utilizados & - & $20 \%$ & $20 \%$ \\
\hline Apoio no BBB & - & $7 \%$ & \\
\hline Emojis de apoio & - & & \\
\hline
\end{tabular}

Fonte: Autores (2021).

\subsubsection{Discurso do sujeito coletivo de cada período}

\section{Discurso do sujeito coletivo 1: janeiro a maio de 2021 (conta oficial do participante)}

No início do programa, percebi que Gil era o que melhor me representava, por ser nordestino e LGBTQIA+, além de alegre, autêntico e carismático. Me representa até mesmo quando perde o controle surta dentro do programa. Junto com Sara e Juliette, o Trio “G3”, são os melhores jogadores, inteligentes, estratégicos e verdadeiros, estou com eles até a final! São os vencedores e têm que ficar longe da Karol para não se contaminar com aquela cobra.

Adoro quando o Gil dança o Tchac Tchac tchá, ele é muito lindo, inteligente e engraçado. E afinal O QUE É BASCULHO? A Pocah bem que mereceu, muito abusada, o Gil merece respeito. O Gil tem que ficar atento com a Sara, ela está manipulando ele e vai levá-lo para o mal caminho. Ver o Gil triste é de partir o coração, a Sara desvirtuou nosso menino e essa Juliette é insuportável.

Alô ADM, avisa lá que é o Gil o grande campeão, ele é muito merecedor e vencedor. Representa muito a comunidade LGBTQIA +. É bom ver o Gil e a Juliette se aproximando novamente, ele estava muito sozinho e precisava voltar a sorrir, mesmo me decepcionando em não votar na Viih Tube, aquela cobra falsa manipuladora. Poxa, Gil... Você avisou para o Fiuk que ela é manipuladora e na hora $\mathrm{H}$, não vota nela... Não te entendo.

Muito injusta a eliminação do Gil, ele deveria estar no mínimo no TOP 3 do programa, foi protagonista em toda sua trajetória e não se rebaixou para basculho. Gil, você é o grande campeão do meu coração. 


\section{Discurso do sujeito coletivo 2: janeiro a maio de 2021 (conta oficial do BBB)}

Desde o início o Gil me representou, além de levar o entretenimento do BBB nas costas. Tem que ser o campeão, ele é uma lenda! E queria que o Boninho manipulasse para o Gil atender o Big Fone, para mandar a Karol para o paredão.

Com a Sarah e o Gil perdendo o favoritismo por falarem mal da Juliette por trás, acreditando na versão da Lumena das situações, nesse momento, o G3 mudou. Contudo eu amo o Gil, ele é uma lenda, apesar de que as atitudes dele me deixaram com um ranço.

Então na sua última semana no programa, o Gil continuou sendo puro entretenimento, foi líder, e no seu quarto tinha um retrato sensacional dele como rei da cachorrada, ele pulou pelado na piscina com o Fiuk e por isso acredito que o Giuk deveria ir para a final. Mas então ele foi eliminado.

\section{Discurso do sujeito coletivo 3: agosto a setembro de 2021}

Ver o Gil regozijando e vigorando, fazendo sucesso é tudo de bom. Ele merece muito! é inteligente, dedicado, guerreiro e acima de tudo merecer! Agora é hora dele desfrutar de todo seu esforço e dar a vida que sua mainha merece. Que família mais linda!

Gil sabe o valor que a educação tem e o quão necessário é o ensino público. Muito lindo ver ele defendendo a educação de forma tão representativa, o Brasil precisa de mais educação urgente, para que mais gente como Gil possa vencer na vida como ele. Saber que ele está indo para os EUA cursar seu doutorado e realizar um sonho de sua vida, me faz sentir como se estiver realizando um sonho também.

O Gil vigorando nos EUA é maravilhoso. Ele é brilhante, inteligente e se Deus quiser vai ser o futuro Ministro da economia do Brasil. Vai BRASIL! Me enche de orgulho ver ele se divertindo e estudando para ter um futuro melhor, mesmo após tanta fama. Que Deus te abençoe e guarde.

\subsubsection{Karol Conká}

\subsubsection{Categorização}

Na categorização das contas relacionadas à Karol Conká, conclui-se que, antes do Big Brother Brasil 21, 68\% dos comentários eram de elogios à imagem do participante.

No período do programa, o maior número de comentários, com $32 \%$ do total, são comentários de alusão a outros participantes. vale ressaltar que, neste período, a equipe da Karol optou por não fazer muitos posts e até por restringir os comentários de alguns, logo, a quantidade de comentários analisadas foi um pouco inferior aos demais.

Após o BBB, a categoria mais comentada, com $46 \%$ dos comentários, é a de comentários de elogios à imagem do participante. O Quadro 7 traz na íntegra os dados sobre a participante Karol Conká: 
Quadro 7 - Categorização dos comentários das contas relacionadas à Karol Conká.

\begin{tabular}{|c|c|c|c|}
\hline KAROL CONKÁ & NOV-DEZ/20 & JAN-FEV/21 & AGO-SET/21 \\
\hline Elogios ao comportamento no BBB & $0 \%$ & $0 \%$ & $0 \%$ \\
\hline Elogios à imagem do participante & $68 \%$ & $15 \%$ & $46 \%$ \\
\hline Críticas ao comportamento no BBB & $0 \%$ & $6 \%$ & $0 \%$ \\
\hline Críticas à imagem do participante & $1 \%$ & $23 \%$ & $1 \%$ \\
\hline Identificação com participante & $1 \%$ & $0 \%$ & $1 \%$ \\
\hline Alusão a outros participantes & $0 \%$ & $32 \%$ & $2 \%$ \\
\hline Alusão a humor (memes) & $1 \%$ & $14 \%$ & $2 \%$ \\
\hline Interesse por produtos utilizados & $1 \%$ & $0 \%$ & $16 \%$ \\
\hline Apoio no BBB & $0 \%$ & $2 \%$ & $0 \%$ \\
\hline Emojis de apoio & $13 \%$ & $1 \%$ & $16 \%$ \\
\hline Outros & $15 \%$ & $7 \%$ & $16 \%$ \\
\hline
\end{tabular}

Fonte: Autores (2021).

\subsubsection{Discurso do sujeito coletivo de cada período}

\section{Discurso do sujeito coletivo 1: novembro a dezembro de 2020}

O que dizer dessa diva? Simplesmente linda, estilosa e lacradora. O que fizeram com a Mari Ferrer foi abominável, e ter a nossa Mamacita expondo isso só mostra como ela é perfeita, temos que pedir justiça.

Amei esse novo álbum da Mamacita arrasando no figurino com a MC Rebeca, perfeitas, adoro as músicas delas, essa parceria não podia dar nada além de um arraso.

Eu adoro ver a Diva no programa "Prazer, feminino" da GNT, a nossa Diva mostrando como ela é maravilhosa no programa, não tem como não achar engraçada e fantástica a reação dela com os "brinquedos".

Amei ver a Mamacita rebolando no maior estilo natalino, do jeitinho que danço também. Te desejo um feliz natal, Mamacita, continue sendo o sucesso que já é.

\section{Discurso do sujeito coletivo 2: janeiro a maio de 2021 (conta oficial do participante)}

A Diva já começou fazendo coisa errada no BBB, não curti a maneira xenofóbica que ela agiu com a Juliette, pelo menos os adms sabem que está errado, tudo bem falar que é normal ser diferente por ser curitibana, mas usar para ser preconceituosa não dá.

Agora a Karol me decepcionou, não adianta a assessoria defender ela, ela continua fazendo coisa errada lá dentro, o que ela faz com o Lucas não dá para aceitar, tortura psicológia não dá. Não tem como consertar essa crise assessoria.

Sempre achei a Karol linda, e ainda acho, mas beleza não define caráter, agora ela está junta do Bill, praticamente viraram o próprio "Cherno Bill”, duas pessoas que não são belas além da aparência. Mesmo assim ainda estamos torcendo por 
você Mamacita, por isso vamos te apoiar e pedir o singelo \#ForaArthur. Oi Diva sei que deve ser difícil no BBB, creio que você vai ter tempo para refletir sobre o que aconteceu, vamos apoiar você, vai ficar tudo bem agora, fique bem.

\section{Discurso do sujeito coletivo 3: janeiro a maio de 2021 (conta oficial do BBB)}

A aproximação da Karol com o Lucas vai dar problemas, ele errou falando que não tinha afinidade com gente branca, e a Karol passa a mão na cabeça do Lucas ele está errado e vai fazer com que o pessoal da casa fique contra ela. Karol ficou falando demais, falou da Juliette e agora tomou, foi a primeira a sair da prova com o Acrebiano, Gil ainda deu uma surra nela. Fico tão triste com uma notícia dessas (ironia). Alguém avisa que a explosiva é a Karol e não a Ju, te amo Ju minha rainha. A Karol reclama que não acordaram ela, ninguém acordou o Lucas, tem que acordar ela por quê?!

Ninguém vai vibrar a liderança da Karol?! Karol no paredão, agora a gente se livra dela. Rejeição histórica, agora o Brasil inteiro comemora. A Karol gostava de defender e passar pano para macho. O Arthur não é como a Karol pensava. Mas ela acertou sobre a Juliette e Sarah, desconfiou delas com razão.

\section{Discurso do sujeito coletivo 4: agosto a setembro de 2021}

Que bom que você voltou Mamacita, e que é bola para frente, não alimente o passado, quero ver a Mamacita Louca e Sagaz de volta quero ver surra. Estou esperando minha sessão de hipnose em Mamacita. Tenho certeza que seu Papacito está em um lugar melhor. Amei você no programa do Whindersson, também gostei no da Thelminha, duas divas.

Como sempre a Mamacita sendo necessária e abordando o machismo e o papel da mulher negra na sociedade. Além disso, soube que você está trabalhando em um novo álbum, espero que fique sabendo que estou esperando ansiosamente por essas músicas, viu?

Nossa Mamacita fazendo um programa com o Mano Brown? Que chique viu. Quando vi aquelas publicações dos seus diferentes visuais, gostei do cabelo rosa. Vi o programa Altas Horas, é doloroso ver você se desculpar como uma criminosa. Amamos você sua linda.Você nos representa muito, \#ForaBolsonaro, lenda, a luta nunca acaba.

Amei ouvir você no esquadrão suicida, se Mamacita fala a gente obedece. Você e a Cuca não tem como recusar. Queremos Mamacita Louca e Sagaz para ontem, espero novos hinos. A música Subida, vai aparecer no FIFA22, estou feliz, mas e o Show de Hipnose (louca e sagaz)?! Estou esperando. Nossa amei a música Subida nossa diva.

\subsection{Análise descritiva}

As parcerias quantificadas dos participantes, durante os períodos de análise; antes, durante e depois do BBB é vista no Quadro 8. A análise de parcerias no Instagram dos participantes foi dividida por períodos e pelo tipo de parcerias, sendo a análise descritiva quantificada pelo número de publicações e quantidade de parcerias. 
Quadro 8 - Quantificação de parcerias.

\begin{tabular}{|c|c|c|c|c|c|c|c|c|c|}
\hline \multirow{2}{*}{ Participante } & \multicolumn{3}{|c|}{ Antes do BBB } & \multicolumn{3}{c|}{ Durante o BBB } & \multicolumn{3}{c|}{ Depois do BBB } \\
\cline { 2 - 10 } & Marcas & Influencers & Produtos & Marcas & Influencers & Produtos & Marcas & Influencers & Produtos \\
\hline Juliette & 0 & 1 & 0 & 15 & 116 & 0 & 24 & 115 & 4 \\
\hline Publicações & 0 & 1 & 0 & 20 & 179 & 0 & 46 & 338 & 25 \\
\hline Gil & 0 & 0 & 0 & 2 & 2 & 0 & 16 & 0 & 2 \\
\hline Publicações & 0 & 0 & 0 & 2 & 2 & 0 & 56 & 0 & 10 \\
\hline K. Conka & 17 & 0 & 2 & 0 & 0 & 0 & 12 & 0 & 2 \\
\hline Publicações & 36 & 0 & 6 & 0 & 0 & 0 & 16 & 0 & 8 \\
\hline
\end{tabular}

Fonte: Autores (2021).

Pode ser observado no quadro que Juliette não utilizou a mídia social para promoção antes do programa, aumentando massivamente o uso durante o programa e fazendo parcerias com marcas e influenciadores. Após o BBB, obteve o crescimento em marcas de $160 \%$ em relação ao período durante o BBB, e iniciou a parceria de seus produtos. A evolução nas parcerias evidenciam resultados da administração informada durante a análise de conteúdo. As principais parcerias estabelecidas entre Juliette e outras pessoas ou marcas, utilizando o co-marketing, foram: WhatsApp, Samsung, Americanas, Avon e L'Occitane.

No caso do Gil, é possível verificar que o mesmo não teve parcerias antes do BBB e obteve apenas 2 durante o BBB, evidenciando o despreparo inicial da administração da rede social, assim como informado na análise de conteúdo. Após a saída do BBB, obteve sucesso na criação de co-marketing, aumentando em nove vezes o número de parcerias com marcas, entre as principais: Vigor, Santander, BIS, CNA e Motorola.

Em contrapartida, Karol Conká já possuía uma conta voltada à promoção de seu conteúdo, porém, durante o BBB, por consequência da crise de imagem, foi necessário apagar todas as publicações do seu Instagram; por este motivo, o período não pôde ser analisado. Observa-se que a parceria com marcas após o BBB reduziu em cerca de $71 \%$ em comparação ao período antes do programa, porém o seu produto (música) se manteve como o inicial.

Já na análise de evolução de seguidores foram elaborados gráficos (Gráfico 1 e 2), com base em dados obtidos com os números de seguidores no Instagram (Desbrava, 2021) e Twitter (Trends Map, 2021) de janeiro de 2021 até a primeira quinzena de outubro de 2021. 
Gráfico 1- Evolução de seguidores no Instagram por participante.

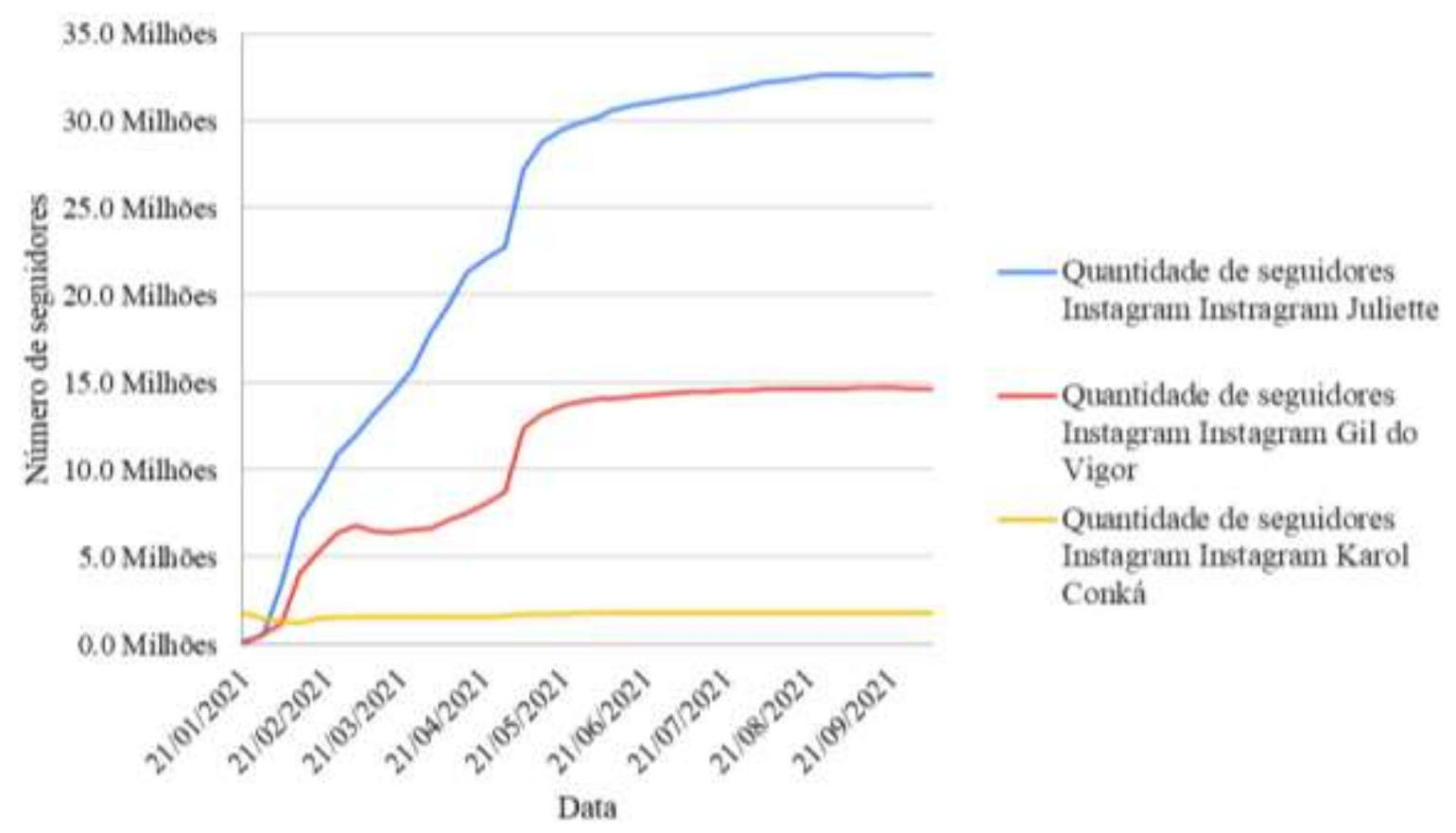

Fonte: Desbrava Data (2021).

No Gráfico acima, é nítida a crescente exponencial dos seguidores na conta de Juliette, vencedora da edição de 2021 do programa. É possível constatar também que Gil do Vigor obteve certo crescimento no seu número de seguidores mas, de maneira moderada. Já Karol Conká, em movimento contrário aos demais, obteve queda no início do programa e pouca evolução desse número após os conflitos ocasionados na edição do reality.

Gráfico 2 - Evolução de seguidores no Twitter por participante.

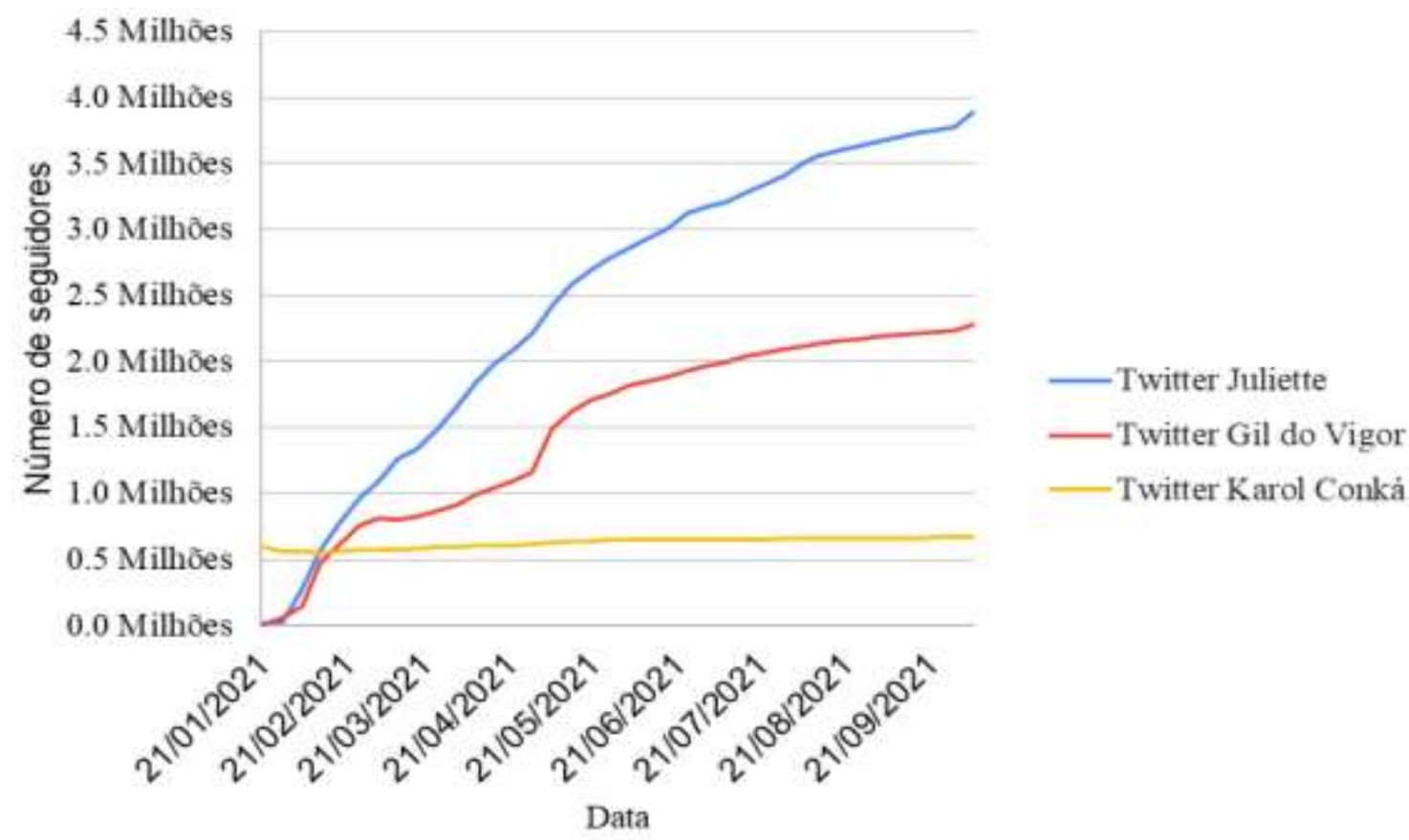

Fonte: Trends Map (2021). 
No Gráfico acima, novamente percebe-se crescente exponencial dos seguidores na conta de Juliette, o crescimento moderado no número de seguidores de Gil e pouco crescimento nos números de Karol Conká.

Nesta análise, foi observado que a evolução dos seguidores do Instagram e do Twitter, de forma geral, aconteceram com um comportamento similar, sendo que a Juliette teve uma grande ascensão em número de seguidores, começando com cerca de 4 mil seguidores e, em 1 mês de programa já possuía mais de 11 milhões de seguidores, e seguiu em ascensão, praticamente sem intercorrências e com grandes picos de crescimento até maio, totalizando cerca de 27 milhões de seguidores no final do programa. E no pós-programa, continuou com um crescimento de seguidores, porém mais tímido, adquirindo 5 milhões de seguidores nos próximos 4 meses, iniciando o mês de outubro com 32 milhões de seguidores.

Após o início do programa, em sua conta @gildovigor no Twitter, o participante Gilberto partiu de um perfil modesto com cerca de 3 mil seguidores, antes do início do BBB 21, para aproximadamente 750 mil apoiadores ao final do primeiro mês de programa. No que diz respeito ao Instagram, o participante obteve um ganho expressivo de apoiadores, atingindo a marca de 6,4 milhões de seguidores no primeiro mês. Este marco está atrelado à forte afinidade com o público nordestino e LGBTQIA+, que rapidamente se identificaram com a história de vida do participante e o elencaram como um dos favoritos a vencer o BBB 21 .

Na primeira quinzena de março, após desentendimentos com as participantes Carla Dias e Juliette, Gil perdeu parte do seu prestígio com o público, resultando em um leve declínio, seguido de uma retomada de crescimento, após a reconciliação entre Gilberto e Juliette, alcançando a marca de aproximadamente 8,7 milhões de seguidores no Instagram e 1,1 milhão no Twitter ao final do mês de abril. Ao final do programa, na primeira semana de Maio, mesmo finalizando sua participação em $4^{\circ}$ lugar, os perfis @ gildovigor, totalizavam 12,3 milhões de apoiadores no Instagram e 1,6 milhões no Twitter. Após o programa, com aparições frequentes em programas televisivos e propagandas publicitárias, a valorização da imagem de Gil refletiu em seu ritmo de crescimento midiático constante nos meses subsequentes, chegando ao mês de Outubro de 2021 com 14,6 milhões de seguidores no Instagram e aproximadamente, 2,2 milhões de seguidores no Twitter.

Dentre os participantes observados, Karol Conká é a única que adentrou ao programa com o status de famosa, possuindo em suas contas no Instagram e Twitter com 1,7 milhões e 590 mil seguidores, respectivamente. Após o início do programa, seu comportamento tempestivo e os conflitos envolvendo o participante Lucas Penteado foram fatores determinantes para a desvalorização da imagem da cantora e, consequentemente, para o declínio de seguidores em redes sociais. Karol foi eliminada em Fevereiro, com 99,17\% de rejeição do votos, um recorde entre todas as edições do reality show e, em suas redes sociais, acumulava 1,4 milhões de seguidores no Instagram e 561 mil seguidores no Twitter.

Após sua participação no BBB, devido à repercussão de seus atos, a cantora focou, primeiramente, em restaurar sua saúde e o bem-estar de sua família, seguindo para sua carreira e imagem. Este processo de recuperação se desenvolveu de forma tímida ao longo dos meses, porém, com um crescimento constante, chegando ao mês de outubro de 2021, com aproximadamente 1,8 milhões de apoiadores no Instagram e 672 mil no Twitter.

\section{Considerações Finais}

A partir deste trabalho, foi possível estudar e compreender profundamente a exposição televisiva dada aos participantes de reality shows. Mais especificamente, foram analisados os impactos que o Big Brother Brasil teve na carreira de Juliette, Gil e Karol Conká. A partir da análise de resultados, é certo que os participantes precisam de uma estratégia nas redes sociais para sustentar uma reputação fora do programa, e, também, o comportamento da pessoa dentro do reality é relevante para a repercussão de sua imagem entre o público. 
Juliette e Gil desenvolveram o marketing pessoal sustentado por i.) um comportamento dentro do BBB 21 que conquistou o público; e ii.) uma gestão das redes sociais Instagram e Twitter, e tiveram muito sucesso durante e após o programa. Alcançaram um número de seguidores expoente, fizeram parcerias com grandes marcas consolidadas no Brasil e conquistaram o apoio de muitos fãs; o sucesso permaneceu em projetos posteriores ao BBB 21, como é o caso do EP de Juliette e do programa independente de Gil no Instagram.

Karol Conká, por outro lado, enfrentou dificuldades durante o programa devido aos mesmos fatores apresentados dos participantes acima. Seu comportamento impactou fortemente sua reputação fora do programa, e a falta de uma gestão estruturada das redes sociais também teve um peso negativo. Com isso, perdeu seguidores, parcerias e o apoio de admiradores, mostrando que ela foi no movimento contrário das outras duas personalidades analisadas.

Conforme discutido na seção de Análise de Conteúdo, o Big Brother Brasil realmente é um amplificador de todas as coisas: o que é bom fica melhor, e o que é ruim fica pior. Ou seja, as ações de Karol julgadas pelo público como negativas tiveram uma má repercussão expressiva entre seus seguidores, em parte por conta do alcance massificado do BBB. Em contrapartida, as ações positivas de Juliette e Gil também foram maximizadas em decorrência da exposição dada pelo Big Brother.

Portanto, o reality show potencializou significativamente a promoção da imagem de seus participantes. Dessa forma, pode-se concluir que a participação no programa representa uma grande oportunidade de Marketing Pessoal; a partir da exposição dada pelo reality, é possível ser valorizado por fãs, marcas e negócios.

A partir dos estudos de caso deste trabalho, conclui-se que o participante tem sua imagem pessoal favorecida por meio do Marketing Digital, quando este é bem utilizado. Embora a hipótese inicial tenha sido confirmada, a compreensão da temática foi aplicada ao concluir que, além do Marketing Digital, o comportamento individual do participante influencia sua imagem como marca de valor para os negócios.

O Big Brother Brasil é um reality show de grande relevância no país. Movimenta negócios envolvendo muito dinheiro, parcerias e muita emoção aos participantes e aos telespectadores. Portanto, é relevante no fator cultural e, também, financeiro. Muito embora sua importância seja demonstrada por números desmedidos, ainda é pouca a contribuição acadêmica em relação ao tema. Por isso, espera-se que este trabalho contribua para a compreensão do fenômeno BBB e seu impacto nos participantes e, também, que sirva como incentivo e inspiração a estudos futuros.

\section{Referências}

Albuquerque, F. D. D.; Costa, M B F. (2020). Gerenciamento do branding por meio de técnicas do marketing pessoal. Open Minds International Journal.

Bardin, L. (1977). Análise de conteúdo. (2011). São Paulo: Edições, 70.

Brittos, V. C.; Barbosa, R. C. (2010). Reality show: o formato audiovisual como estratégia estética na busca pela liderança. Revista de Estudos da Comunicação.

Bucklin, L. P.; Sengupta, S. (1993). Organizing successful co-marketing alliances. Journal of marketing.

Data, D. (2021). Desbrava Data. https://plataforma.desbravadata.com.br/\#/social.

Fernandes, A. S. M. (2017). Centralidade e Detecção de Grupos em Redes Sociais Multilayer - uma aplicação ao Co-Marketing. https://repositorioaberto.up.pt/bitstream/10216/108168/2/224361.pdf

Folayan, B. J., Ajibade, O., Dipo-Adedoyin, O., Onayinka, T. S., \& Folayan, T. T. (2021). The Big Brother NaijaTV Reality Show as Coordinate of Media Functions and Dysfunctions. arXiv preprint arXiv:2104.14532.

Folhapress (2020). BBB 20 foi o programa que mas gerou tuítes no mundo em 2020. https://www.folhape.com.br/cultura/bbb-20-foi-o-programa-que-maisgerou-tuites-no-mundo-em-2020-confira/164972/.

Guinness World Records (2020). Most public votes received by a television programme. https://www.guinnessworldrecords.com.br/world-records/mostpublic-votes-received-by-a-television-programme. 
Research, Society and Development, v. 11, n. 1, e24011124659, 2022

(CC BY 4.0) | ISSN 2525-3409 | DOI: http://dx.doi.org/10.33448/rsd-v11i1.24659

Isto É Dinheiro (2020). Apetite de Merchandising. https://www.istoedinheiro.com.br/apetite-de-merchandising/.

Jacobson, J. (2020). You are a brand: social media managers' personal branding and "the future audience". Journal of Product \& Brand Management.

Kotler, P.; Kartajaya, H.; Setiwan, I (2017). Marketing 4.0: do tradicional ao digital. Sextante.

Lefevre, F.; Lefevre, A. M. C. (2006). O sujeito coletivo que fala. Interface-Comunicação, Saúde, Educação, 10, 517-524.

Map, T. (2021). Trends Map. Disponível em: https://www.trendsmap.com/twitter/user/gildovigor.

Map, T. (2021). Trends Map. Disponível em: https://www.trendsmap.com/twitter/user/juliette.

Map, T. (2021). Trends Map. Disponível em: https://www.trendsmap.com/twitter/user/karolconka.

TV, O. D. (2021). Estreia do BBB 21 alcançou mais de 43 milhões de telespectadores no painel nacional. https://observatoriodatv.uol.com.br/audiencia-datv/estreia-do-bbb-21-alcancou-mais-de-43-milhoes-de-telespectadores-no-painel-nacional.

Toledo, L. A., Piccioli, C. F.; Montesano, J. G.; Carbone, L. S.; Costa, T. S. D. O. (2021). O Instagram como estratégia de marketing: um estudo na empresa Chocolates Garoto. Revista da Extensão e Iniciação Científica da UNISOCIESC.

Criativos, P. (2021). Festa do pijama McDonald 's se torna o merchan mais efetivo da história. https://www.publicitarioscriativos.com/festa-do-pijamamcdonalds-se-torna-o-merchan-mais-efetivo-da-historia/. Acesso em: 04 abr. 2021.

Rein, I., Kotler, P., Hamlin, M., \& Stoller, M. (2006). High visibility: Transforming your personal and professional brand.

Rocha, D. C. (2009). Reality TV e reality show: ficção e realidade na televisão. E-Compós.

Silva, A. H.; Fossá, M. I. T. (2015). Análise de conteúdo: exemplo de aplicação da técnica para análise de dados qualitativos. Qualitas Revista Eletrônica.

Silva, F. E. D.; Sousa, F. R. L. D.; Tavares, F. B. R.; Silva, I. B. D. (2019). Marketing Pessoal: Desenvolvimento do Indivíduo através de Estratégias e Planejamento. Research, Society and Development.

Trends, G.(2021). Pesquisa de palavras chave: méqui; mc donalds; McDonald's. https://trends.google.com.br/trends/explore?date=today\%203$\mathrm{m} \& \mathrm{geo}=\mathrm{BR} \& \mathrm{q}=\mathrm{m} \% \mathrm{C} 3 \%$ A9qui,mc\%20donalds, $\% 2 \mathrm{Fm} \% 2 \mathrm{~F} 07 \mathrm{gyp} 7$.

Umami, Z., \& Darma, G. S. (2021). Digital marketing: engaging consumers with smart digital marketing content. Jurnal Manajemen dan Kewirausahaan, 23(2), 94-103. 